\title{
« Die Erstaufführung einer tschechischnationalen Oper ». Jenůfa à Vienne
}

Gaëlle Vassogne, "Die Erstaufführung einer tschechischnationalen Oper" Jenůfa in Wien

Gaëlle Vassogne, "Die Erstaufführung einer tschechischnationalen Oper"Jenůfa in Vienna

\section{Gaëlle Vassogne}

\section{OpenEdition}

\section{Journals}

Édition électronique

URL : https://journals.openedition.org/austriaca/716

DOI : 10.4000 /austriaca.716

ISSN : 2729-0603

\section{Éditeur}

Presses universitaires de Rouen et du Havre

\section{Édition imprimée}

Date de publication : 1 décembre 2019

Pagination : $77-90$

ISBN : 979-10-240-1454-8

ISSN : 0396-4590

\section{Référence électronique}

Gaëlle Vassogne, « «Die Erstaufführung einer tschechischnationalen Oper ». Jenůfa à Vienne »,

Austriaca [En ligne], 88-89 | 2019, mis en ligne le 31 décembre 2020, consulté le 24 octobre 2022. URL : http://journals.openedition.org/austriaca/716 ; DOI : https://doi.org/10.4000/austriaca.716 
Gaëlle VAssogne

Institut des langues et des cultures d'Europe et d'Amérique,

Centre d'études et de recherches allemandes et autrichiennes

contemporaines (ILCEA, CERAAC), Université Grenoble Alpes

\section{«Die Erstaufführung einer tschechischnationalen Oper» Jenůfa à Vienne}

Inspirée d'un fait divers, l'intrigue de Jenůfa est connue ${ }^{1}$ : abandonnée par Števa, Jenůfa donne naissance à un fils, enfant illégitime que Kostelnička, mère adoptive de Jenůfa, noie dans le ruisseau pour permettre le mariage de Jenůfa et de Laca, demi-frère de Števa. Le corps de l'enfant est découvert alors que l'union va être célébrée : Kostelnička confesse son crime et Jenůfa, qui comprend qu'elle a agi par amour pour elle, décide de lui pardonner.

Janáček a travaillé à Jenůfa entre 1894 et $1903^{2}$; sa complétion coïncide avec la mort de sa fille Olga et la partition pour voix et piano porte la dédicace : «À ta mémoire, Olga.» Jenuifa vit le jour dans des circonstances difficiles et son parcours ne le fut pas moins : l'opéra devint bientôt un miroir de son époque, une victime de rivalités d'abord artistiques puis nationales.

\section{De Brno à Prague}

Représenté pour la première fois en janvier 1904 à Brno, Jenưfa dut attendre 1916 pour avoir les honneurs du Théâtre national de Prague. Janáček y avait soumis son œuvre ${ }^{3}$, mais essuya un refus que le directeur, Gustav Schmoranz, justifia par le faible potentiel commercial de l'œuvre ${ }^{4}$. Il semble que le motif ait été plus personnel : la programmation

1. Comme la pièce qui l'a inspiré, l'opéra porte le titre tchèque Její Pastorkyňa (Sa fille adoptive). La traduction de Max Brod s'intitule Jenuifa et c'est sous ce titre que l'œuvre a conquis les scènes internationales.

2. Jaroslav Vogel, Leoš Janáček. Leben und Werk, Praha, Artia, 1958, p. 188 et suiv.

3. Voir Jaroslav Vogel, op. cit., p. 207, et suiv., et John Tyrrell, Janáček's Operas. A Documentary Account, Princeton, Princeton University Press, 1992, p. 48 et suiv.

4. Voir Charles Susskind, Janáček and Brod, New Haven, Yale University Press, 1985, p. 25. 
était la prérogative du chef d'orchestre, le compositeur Karel Kovařovic, dont Janáček avait tourné en ridicule l'opéra Ženichové dix-sept ans plus tôt ${ }^{5}$. Kovařovic eut la rancune tenace. Après le succès de Jeni̊fa à Brno, Janáček tenta à nouveau sa chance : dans une lettre du 9 février 1904, il se plaignit de l'injustice dont son œuvre avait été victime, peut-être, s'interrogeait-il, parce qu' il s'agissait d'un opéra morave ${ }^{6}$ ? Janáček ne jouissait en effet à Prague que d'une renommée limitée de folkloriste ${ }^{7}$. Mais, selon ce que rapporta Schmoranz à Karel Š́pek ${ }^{8}$, Kovařovic jugeait ainsi l'opéra : «eine Mischung von Bestrebungen nach einer forcierten Novität des Stils, äußerstem Primitivismus, der an kompositionelle Unfähigkeit grenze, und von Altmodischem und längst Überwundenem ${ }^{9}$.»

Janáček tenta alors sa chance au Hofoper de Vienne, espérant sans doute que son directeur, Gustav Mahler, né à la frontière entre la Bohême et la Moravie, lui serait plus favorable. Il l'invita à venir assister à une représentation à Brno et joignit à sa demande deux recensions publiées dans la presse tchèque. Le baron Pražák, membre du Reichsrat et du Landtag de Moravie, appuya sa requête. Le 6 décembre 1904, Mahler déclina l'invitation, mais proposa ceci : «Vielleicht kann mir ein Clavierauszug mit deutschem Texte, da ich der böhmischen Sprache nicht mächtig bin, behufs Einsicht zugeschickt werden ${ }^{10}$.»

Mais une telle partition n'existait pas. Jenůfa dut encore patienter pour connaître la consécration. Lorsque la première guerre mondiale éclata, les sympathies panslaves de Janáček lui valurent de faire l'objet d'une surveillance de la part des autorités impériales. Le Cercle russe, qu'il avait contribué à fonder à Brno et dont il était l'un des présidents, fut dissous. L'épouse de Janáček, Zdeňka, alla même jusqu'à brûler, sans l'en informer, la correspondance personnelle de Janáček avec ses amis résidant en Russie ou en Croatie et à dissimuler avec du lierre l'inscription en russe sur la tombe d'Olga. Le refus de Janáček de confier aux institutions viennoises les partitions des chansons populaires qu'il

5. Leoš Janáček, «Ženichové», Hudební listy, 15 janvier 1887, p. 54.

6. Voir John Tyrrell, Janáček's Operas, op. cit., p. 58 et suiv.

7. Hans Hollander, Leoš Janáček. Leben und Werk, Zürich, Atlantis, 1964, p. 61.

8. De son vrai nom Josef Peška, écrivain, critique et librettiste de Kovařovic.

9. Voir Hans Hollander, op. cit., p. 62.

10. Voir Clemens Höslinger, "Zur Vorgeschichte der Wiener Jenufa-Premiere», Österreichische Musikzeitung, 1972, p. 409. Certains critiques ont vu dans cette affirmation un mensonge bien pratique. Dans son ouvrage consacré à Janáček, Patrice Royer qualifie la lettre de Mahler de «dérobade hypocrite quand on sait qu'à Hambourg, Mahler révisait la traduction allemande de La fiancée vendue et qu'il comprenait évidemment le tchèque» (Leoš Janáček, Paris, Bleu Nuit, 2004, p. 74, note). 
avait rassemblées pour le projet Das Volkslied in Österreich ne fit rien pour atténuer cette méfiance ${ }^{11}$ : il justifia son refus par le fait qu'elles appartenaient à la nation tchèque et devaient demeurer en Moravie ${ }^{12}$.

La représentation à Prague de Jeni̊fa fut rendue possible par une conspiration amicale : František Veselý, gérant de la station thermale de Bohdaneč, et son épouse, la cantatrice Marie Calma, réussirent à persuader Karel Š́pek et Gustav Schmoranz (le premier était natif de Bohdaneč, le second y était venu prendre les eaux) de faire pression sur Kovařovic afin qu'il revienne sur son refus ${ }^{13}$. Kovařovic accepta que Marie Calma lui chantât quelques extraits et donna son accord $^{14}$, sous réserve de modifications visant à rajouter plus de «liant et de fluidité» à l'œuvre afin d'augmenter «sa puissance dramatique ${ }^{15}$ ». Janáček répondit que Kovařovic pouvait «effectuer toutes les modifications qu'il jug[eait] nécessaires» : «J'accepte tout avec gratitude», écrit-il ${ }^{16}$.

Janáček eut également maille à partir avec la censure. Dans une lettre du 19 mai 1916, il relate à son épouse que, pour éviter toute critique de l'armée impériale (nous sommes après tout en pleine guerre et les cas de désertion, bien que relativement rares, sont bien réels), il a proposé aux autorités de remplacer, dans le chœur des conscrits de l'acte I, le vers «musím být vojáček» (Il faut que je sois soldat) par «já neboráček rád budu vojáček» (moi, pauvre bougre, je serai heureux d'être soldat) $)^{17}$.

11. Le projet avait vu le jour en 1902 à l'instigation de la maison d'édition Universal sous l'égide du ministère autrichien des Cultes et de l'Éducation. Janáček fit ainsi la connaissance d'Emil Hertzka, président des éditions Universal. Voir Jiří Vysloužil, «Leoš Janáček und Wien », Studien zur Musikwissenschaft, n 41, 1992, p. 257-285.

12. Voir Mirka Zemanová, Janáček. A Composer's Life. London, John Murray, 2002, p. 116 et suiv.

13. Voir Jiří Ort, Leoš Janáček. Der späte Wilde. Liebe und Leben in Opern und Briefen, Kassel et al., Bärenreiter, 2005, p. 63 et suiv. ; Mirka Zemanová, Janáček. A Composer's Life, op. cit., p. 117 et suiv. ; John Tyrrell, Janáček's Operas, op. cit., p. 65 et suiv ; Hans Hollander, Leoš Janáček. Leben und Werk, op. cit, p. 62-63.

14. Marie Calma en informa Janáček le 9 décembre 1915 (Korespondence Leoše Janáčka s Marií Calmou a MUdr. Františkem Veselým (La correspondance de Leoš Janáček avec Marie Calma et František Veselý), Praha, Orbis, 1951, p. 57 et suiv.). Elle lui fit part du désir de Kovařovic de la voir chanter le rôle de Jenůfa qui fut finalement confié à Kamila Ungrová. Marie Calma ne pardonna jamais à Janáček (voir une lettre à Janáček datée du 25 février 1916, ibid., p. 66 et suiv.)

15. Lettre de Veselý à Janáček, 9 décembre 1915, ibid., p. 59 : «[... „aby dílo dostalo spád a proud a získalo na dramatičnosti“.»

16. Lettre de Janáček à Veselý, 10 décembre 1915, ibid., p. 60 : «Píši ted’ i p. Kovařovicivi, aby upravoval škrty, jak za dobré uzná. V̌se s povděkem přijmu.»

17. John Tyrrell, Janáček’s Operas, op. cit., p. 86. 
La première eut lieu le 26 mai 1916. L’accueil fut triomphal. Janáček fut célébré comme un véritable patriote ${ }^{18}$, comparé à Smetana et l'œuvre qualifiée de nouvelle Fiancée vendue. La seule voix discordante fut celle du musicologue Zdeněk Nejedlý (grand admirateur de Smetana, qui devint plus tard ministre de la culture sous Klement Gottwald) : «Janáček rassemble suffisamment de matière mais ne sait qu'en faire ${ }^{19}$.»

\section{De Prague à Vienne}

Ce triomphe ouvrit à Jenůfa les portes de la reconnaissance internationale. Le rôle joué par Max Brod a été maintes fois dépeint ${ }^{20}$. C'est l'article qu'il publia dans la Die Schaubühne qui attira l'attention du public germanophone. Il y insistait sur l'aspect national de l'œuvre dans laquelle "le génie du peuple s'exprime dans chaque mesure», mais surtout sur son caractère universel :

Die Musik, bis dahin von scharfer nationaler Ausprägung (ich nenne Janacek gern einen-mährisch-slowakischen Smetana [...]), wird hier ganz allgemeine, nur musikalische Musik, die Zwischenstufe der Ethnographie hat sich in den großen Ozean der Humanität ergossen ${ }^{21}$.

L'avocat Jan Löwenbach fit parvenir une copie de cet article à Janáček en lui suggérant de trouver un éditeur allemand. Löwenbach lui-même approcha B. Schott's Söhne. Durant la même période à la fin de 1916, Janáček conduisait des négociations parallèles avec Emil Hertzka. Une lettre de Hertzka à Janáček du 22 novembre 1916 révèle que Brod fut à l'origine de ces négociations :

Ich war vor wenigen Tagen in Prag und habe [...] von dem ausserordentlichen Erfolg gehört - Herr Dr Max Brod war es, der mir begeistert von Ihrem Werk sprach! -, den Ihre Oper „Pastorkyňa“ am Böhmischen Nationaltheater hatte.

18. «„Její pastorkyňa“. Poznámká o autoru a díle», Národní listy, 26 mai 1916, p. 1 : «Dvé lásky dělí se již v mládí o jeho bytost : láska k hudbě a laská k národu» (Depuis son enfance, deux amours se partagent son être : l'amour de la musique et l'amour de la nation).

19. Zdeněk Nejedlý, «Její pastorkyňa», Smetana, 4 août 1916, p. 121 : «Janáček však nasbirá si sice dosti materialu; ale nedovede $z$ něho nic udělati.»

20. En particulier par Max Brod lui-même, dans Streitbares Leben, 1884-1968, München et al., Herbig, 1969, et dans Leoš Janáček. Leben und Werk, Wien, Wiener Philharmonischer, 1925. Voir également Charles Susskind, Janáček and Brod, op. cit.

21. Max Brod, «Tschechisches Opernglück», Die Schaubühne, 16 novembre 1916, p. 461 et 458. 
[...] Ich möchte heute bei Ihnen anfragen, ob Sie bereit wären, uns Ihre Oper für die deutschen Bühnen zu überlassen, in welchem Falle wir durch einen erstklassigen deutschen Übersetzer eine deutsche Übersetzung anfertigen lassen und trachten würden, das Werk an einer ersten deutschen Opernbühne baldigst herauszubringen ${ }^{22}$.

Janáček pencha en faveur des éditions Universal et obtint l'accord de Brod pour réaliser la traduction ${ }^{23}$. Il s'agissait maintenant d'assurer le succès commercial de l'opération : pour ce faire, Hertzka comptait sur une représentation de l'opéra, en allemand, sur la scène du K. u. k Hofoper. Il prévoyait de se rendre à Prague pour assister à la représentation, au théâtre allemand, de la Tragédie florentine d'Alexander von Zemlinsky et de Höllisch Gold de Julius Bittner, opéras dont Universal avait publié les partitions. Schmoranz programma une représentation de Jenưfa au Théâtre national le 4 mars 1917 et y assista en compagnie de Bittner, du chef d'orchestre du Hofoper, Hugo Reichenberger, et du critique du quotidien Fremdenblatt, Richard Specht. Si l'on en croit Brod, les réactions furent mitigées, les hôtes viennois étant d'opinion qu'un opéra relatant le meurtre d'un enfant pourrait choquer le public viennois ${ }^{24}$. Janáček partageait l'inquiétude de Brod, mais Hertzka le tranquillisa : "Im Großen Ganzen hat beiden Herren Ihr Werk gefallen und ich glaube, daß Herr Specht darüber auch gut schreiben wird. [...] Das wichtigere Urteil in dieser Sache ist das des Herrn Hofkapellmeister Reichenberger und dieses ist durchaus günstig ausgefallen $n^{25}$."

La critique de Specht fut en effet très positive ${ }^{26}$ et il en fut de même pour le rapport adressé par Reichenberger au directeur du Hofoper, Hans Gregor :

Textlich, musikalisch und hinsichtlich Aufführung [...] ein künstlerisches Erlebnis! Die nur etwas brutale Handlung [...] wirkt ungeheuer packend, die Musik ist das Werk eines Naturtalentes allerersten Ranges. [...] Ich hoffe, daß es dem Übersetzer Max Brod gelingen wird [...] den von der musikalischen Wirkung unzertrennlichen, rhythmisch eigenartigen Tonfall der czechischen

22. Leoš Janáček, Briefe an die Universal Edition, Ernst Hilmar (éd.), Tutzing, Hans Schneider, 1988, p. 15.

23. L'épisode est relaté par Max Brod dans son autobiographie : Streitbares Leben, op. cit., p. 270 et suiv. Voir aussi Leoš Janáček, Briefe an die Universal Edition, op. cit., p. 17.

24. Voir Max Brod, Streitbares Leben, op. cit., p. 272.

25. Hertzka à Janáček, 12 mars 1917, Korespondence Leoše Janáčka s Maxem Brodem (La correspondance de Leoš Janáček avec Max Brod), Praha, Státní Nakladatelství Krásné Literatury, 1953, p. 241.

26. Richard Specht, «Neue Opern in Prag», Fremdenblatt, 15 mars 1917, p. 1 et suiv. 
Sprache auch im Deutschen wiederzugeben. Unter diesem Vorbehalt empfehle ich dringendst die Annahme ${ }^{27}$.

Pour tenter de convaincre Gregor, Hertzka utilisa l'argument politique et écrivit à Gregor :

Es unterliegt keinem Zweifel, daß Janáčeks Oper das Bedeutendste ist, was die böhmische Bühne seit Smetanas "Verkaufter Braut" hervorgebracht hat. [...] [Ich] würde es mit großer Freude begrüßen, wenn das Werk zuallererst in Wien in deutscher Sprache erklingen würde. Ich habe die bestimmte Empfindung, daß eine derartige Aufführung - von dem künstlerischen und musikalischen Standpunkte ganz abgesehen - im Verlaufe der nächsten Zeit hier von ganz besonderer Bedeutung sein und mit beitragen würde, die sehr ersehnte nationale Annäherung zu fördern ${ }^{28}$.

Les négociations traînèrent ${ }^{29}$, mais, en juin 1917, Hertzka put informer Janáček que le Hofoper acceptait de représenter Jenůfa. La première, d'abord prévue en janvier 1918, dut être déplacée au 16 février, car Maria Jeritza, qui devait chanter le rôle-titre, était souffrante. Ce délai plaça Jenưfa au cœur d'une controverse politique.

\section{«Die Unterdrückung der Willensäußerung einer Nation»}

Le 6 janvier 1918, les membres tchèques du Reichsrat et des Landtage de Bohême, Moravie et Silésie promulguèrent une déclaration dans laquelle ils accusaient le gouvernement impérial de nier les droits des Tchèques à l'auto-détermination et affirmaient leur volonté de créer un État pour les Tchèques et les Slovaques. Le terme tchèque samostátnost indique qu'il s'agissait d'une déclaration d'indépendance. Le gouvernement de Vienne interdit la publication du texte et le ministre-président Ernst Seidler von Feuchtenegg dut faire face à une motion de censure, déposée par le député František Staněk, au motif que cette interdiction représentait

27. Haus-, Hof- und Staatsarchiv, Oper 198/1917, cité dans Clemens Höslinger, «Zur Vorgeschichte der Wiener Jenufa-Premiere», Österreichische Musikzeitung, 1972, p. 410.

28. Cité ibid., p. 410 et suiv. Nous soulignons.

29. Ce délai semble avoir avant tout été dû à ce que Reichenberger, au grand déplaisir de Brod, voulait modifier la traduction. Voir Korespondence Leoše Janáčka s Maxem Brodem, op. cit., p. 30 et suiv. ; Meinhard Saremba, Leoš Janáček. Zeit. Leben. Werk. Wirkung, Kassel et al., Bärenreiter, 2001, p. 280 et suiv. ; Tereza Hrdlická, « „Das Möglichste an Sangbarkeit und Sprachgewandtheit“. Neue Erkenntnisse zur Entstehung der deutschen Übersetzung von Janáčeks Oper „Jenufa“ von 1918», Österreichische Musikzeitschrift, $\mathrm{n}^{\mathrm{o}} 2,2003$, p. 18-27. 
une atteinte inacceptable à la liberté d'expression d'une nation. Pour éviter son adoption, qui aurait conduit à la chute du gouvernement, Seidler annonça, à l'ouverture de la séance du 29 janvier 1918, que la « déclaration de l'Épiphanie» pouvait être rendue publique ${ }^{30}$. Le social-démocrate Karl Seitz déclara que son parti ne pouvait apporter son soutien aux Tchèques :

Insoweit nämlich dieser Antrag [Staněks] sich gegen die Konfiskation der Deklaration der böhmischen Abgeordneten wendet [...], ist er gegenstandslos geworden [...] Insofern jedoch gewisse Bestrebungen der tschechischen Parteien abgewehrt werden, die Kronländer Böhmen, Mähren und Schlesien zu einem staatsrechtlichen Ganzen [...] zu vereinigen und damit die Deutschen in diesen Landern einfach einer nationalen Mehrheit auszuliefern, sind wir mit den Ausführungen des Herrn Ministerpräsidenten einverstanden, denn wir sind selbstverständlich gegen diese Bestrebungen.

Staněk réagit violemment :

Sie sind auf die Ausrottung der slawischen Völker ausgegangen. Das werden sie nicht mehr machen, solange wir hier in diesem Hause stehen, in Österreich und in ganz Mitteleuropa und zu der ganzen Welt, das werden sie sich nicht mehr unterstehen ${ }^{31}$.

Pour les députés tchèques, la publication de la déclaration ne réglait pas la question de principe et ils insistèrent pour que la motion fût soumise à un vote qu'ils perdirent, par 155 voix contre 105 .

Les journaux tchèques et allemands saluèrent la levée de l'interdiction, dans des termes bien sûr différents ${ }^{32}$. Bien qu'évidemment en désaccord avec le contenu de la déclaration, l'ensemble de la presse viennoise jugeait absurde d'interdire la publication d'une position déjà connue de tous. L'Arbeiter-Zeitung publia, en une, un article dans lequel on pouvait lire :

Die ganze Eselei der Zensur ist da sichtbar geworden. Die Resolution [...] liegt nun im Wortlaut vor, und man fragt vergeblich, was da eigentlich Neues oder Gefährliches unterdrückt werden sollte. Die Tschechen verlangen darin den selbständigen tschechischen Staat [...]: das ist weder neu, denn sie haben es im Abgeordnetenhause oft genug gesagt, noch irgendwie gefährlich, weil die Vorstellung, die Rechte aller Nationen in dem Instrument zu lösen, das Europa den Frieden gibt, so ziemlich überall um sich greift. [...] Was soll damit erreicht werden,

30. Stenographisches Protokoll, Haus der Abgeordneten, XXII. Session, 55. Sitzung. Dienstag, den 29. Jänner 1918, p. 2906 et suiv.

31. Ibid., p. 2906-2908.

32. L'article, publié en une des Národní listy du 29 janvier 1918, fut censuré. 
daß man es verschweigt, daß man es unterdrückt, daß man es auszusprechen hindert? ?3 $^{33}$

Le Neues Wiener Journal la considérait comme contre-productive :

Im Lichte der Öffentlichkeit verlieren sogar staatsrechtliche Deklarationen alle historisch-gespenstige Unheimlichkeit, und deutlich erkennbar werden die ganz unmöglichen Phantasien und Zügellosigkeiten eines überhitzen Nationalismus ${ }^{34}$.

Le Prager Tagblatt souligna quant à lui le succès de cette «reculade» : la décision, forcée, de Seidler eut le mérite d'apporter à ce dernier le soutien des Allemands face aux «manœuvres politiques» des Tchèques que la presse allemande fut unanime à condamner ${ }^{35}$. La Neue Freie Presse parla d'un «revanchisme tchèque ${ }^{36}$ ", le Neues Wiener Journal affirma que cette politique n'était pas seulement hostile à l'Empire austro-hongrois mais conduisait aussi à l'isolement des Tchèques : "Isoliert bleiben sie ein kleines Volk, das um seine heute angestrebte Souveränität jede Stunde kämpfen müßte, ein Kleinstaat, weder politisch noch wirtschaftlich lebensfähig ${ }^{37}$.» Les sociaux-démocrates se livrèrent à une attaque en règle :

Man [wird] es allmählich müde, jeden Tag von [...] einem neuen Begehren des Herrn Staněk gequält zu werden. Insbesondere die Vorstellung der Tschechen, daß sie bei jedem ihrer Einfälle auf die deutschen Sozialdemokraten rechnen können, muß ernstlich zerstört werden ${ }^{38}$.

\section{«Eine tschechischnationale Oper»}

Ce contexte (et celui des négociations du traité avec la Russie) joua un grand rôle dans la réaction de certains députés nationalistes pour qui la représentation d'un "opéra national tchèque» au Hofoper était une injure à la nation allemande. Le 29 janvier, jour où la motion de Staněk devait être soumise au vote du Reichsrat, seize députés du Deutscher Nationalverband interpellèrent le ministre des Cultes et de l'Éducation sur le sujet. Ils s'insurgeaient contre la représentation d'œuvres de « compositeurs étrangers », au rang desquels Verdi et Gounod, mais aussi Smetana et Janáček : il s'agissait selon eux d’une «dénationalisation»

33. «Die voreilige Unterdrückung», Arbeiter-Zeitung, 30 janvier 1918, p. 1.

34. «Die Irrwege der tschechischen Politik», Neues Wiener Journal, 30 janvier 1918, p. 2.

35. «Der erfolgreiche Rückzug», Prager Tagblatt, 30 janvier 1918, p. 1.

36. «Die czechische Revanchetaktik im Abgeordnetenhaus», Neue Freie Presse, 30 janvier 1918, p. 8.

37. «Die Irrwege der tschechischen Politik», Neues Wiener Journal, 30 janvier 1918, p. 2.

38. «Verhandlungen des Abgeordnetenhauses», Arbeiter-Zeitung, 30 janvier 1918, p. 3. 
du Hofoper et de favoritisme envers les Tchèques qui s'étaient rendus coupables de "honteuses trahisons»: "die geplante Aufführung in der Jetztzeit bedeutet eine Provokation der Deutschen Wiens und es kann durch die beabsichtigten tschechischnationalen Kundgebungen $z u$ den schlimmsten Gegendemonstrationen kommen ${ }^{39}$.»

Janáček s'inquiéta beaucoup de cette interpellation :

Soeben lese ich die Interpel[l]ation der Abg. Schürff und Wedra! [...] Auf so einen Standpunkt sich zu stellen! Was ist da zu tun? Von Demonstrationen ist doch keine Spur. [...] Wie wird sich zur Interpel[l]ation Direktor Gregor stellen? Wie die Intendanz und der Minister? Wie die Tagesblätter? [...] Man freut sich über die Annahme aber das ist eine reine Kunstfreude [...]. Aber politisch das zu verwerten wäre doch ein Unsinn: über so etwas ist man doch zu erhaben, politisch zu reif ${ }^{40}$.

La presse viennoise partagea ce point de vue. Si certains journaux se contentèrent de mentionner l'interpellation, sans faire de commentaires $^{41}$, d'autres réagirent de façon très explicite. L'Arbeiter-Zeitung qualifia ainsi les deux principaux signataires, les députés Schürff et Wedra, de «poseurs les plus stupides» du Reichsrat et poursuivit :

$Z u$ den "fremdnationalen Komponisten" ist nach ihrer Meinung auch Smetana zu rechnen, [...], [der] Komponist eines Volkes, das doch zu Österreich gehört! Weiter kann der deutschnationale Kretinismus schon nicht gehen ${ }^{42}$ !

Pour le Neues Wiener Journal, le Hofoper, une «institution impériale», devait être ouverte à tous les peuples d'Autriche-Hongrie :

Wie wenig berechtigt [...] eine Stellungnahme gegen tschechische Komponisten ist, geht schließlich auch daraus hervor, daß beispielweise die Wagner- oder RichardStrauß-Opern im tschechischen Nationaltheater in Prag immer und noch jetzt besonders glanzvoll zur Aufführung gebracht werden ${ }^{43}$.

39. «Anfrage der Abgeordneten Dr. Schürff, Dr. Waber, Wedra und Genossen an Seine Exzellenz den Herrn Minister für Kultur und Unterricht, betreffend die Bevorzugung fremdnationaler Komponisten seitens der Leitung des k.k. Hofoperntheaters in Wien. 55. Sitzung der XXII. Session am 29. Jänner 1918.»

40. Leoš Janáček à Emil Hertzka, 30 janvier 1918, dans Briefe an die Universal Edition, op. cit., p. 76 et suiv.

41. Voir Prager Tagblatt («Hofoper und Nationalität», 30 janvier 1918, p. 4) et Neues Wiener Tagblatt («Ausländische Komponisten in der Hofoper. Eine Anfrage im Abgeordnetenhaus», 30 janvier 1918, p. 10).

42. «Tschechische Werke in der Wiener Hofoper», Arbeiter-Zeitung, 30 janvier 1918, p. 6.

43. «Die Bevorzugung fremdnationaler Komponisten in der Hofoper. Eine Anfrage im Abgeordnetenhaus », Neues Wiener Journal, 30 janvier 1918, p. 6. 
Mais certains journaux apportèrent à cette interpellation un soutien plus ou moins affirmé. Le Fremdenblatt fit précéder une retranscription du texte de cette remarque :

Man mußzugeben, daß die gegen die Leitung unserer Hofoper erhobenen Vorwürfe keineswegs ungerecht sind. [...] Aufführungen von feindlichen, wenn auch toten Opernkomponisten [müßten sich] vermeiden lassen, zugunsten der Förderung der deutschen Komponisten ${ }^{44}$ !

L'attaque la plus virulente vint du Deutsche Zeitung Bohemia qui condamnait le soutien apporté par la presse viennoise à Jenůfa (expression du «nationalisme tchèque»), rejetant, avec une pointe d'antisémitisme, l'argument selon lequel c'était un Allemand de Prague qui avait attiré l'attention internationale sur Jenưfa : «Da sei nun ein für allemal festgestellt, daß Max Brod [...] gar nicht deutsch sein will.» Et de conclure :

Für die weitesten Kreise des tschechischen Volkes ist die Aufführung des neuen Musikwerks in der Wiener Hofoper nur nebenbei eine künstlerische Tat, vor allem eine politische Eroberung. Drum die Behauptung, daß die Wiener Hofoper keine deutsche, sondern eine österreichisch-internationale Kunststätte sei, eine Anschauung, gegen die gerade wir Deutschen von der Sprachgrenze nicht scharf genug Front machen können ${ }^{45}$.

La presse tchèque quant à elle passa l'affaire sous silence ou réagit ironiquement. Le quotidien Národni listy proposa ainsi un boycott des opérettes viennoises ${ }^{46}$. Pour Janáček, le pire n'était pas l'interpellation au Reichsrat : "noch mehr schmerzt mich eine Notiz in Národní listy, wo der Rauswurf der schlüpfrigen Wiener Operetten als Vergeltungsmaßname vorgeschlagen wird. Jenüfa und Wiener Operetten in eine Reihe stellen ${ }^{47}$ !» Dans une interview au Neues Wiener Journal, Hans Gregor

44. «Der Spielplan unserer Hofoper. Eine Anfrage im Abgeordnetenhaus», Fremdenblatt, 30 janvier 1918, p. 7.

45. "Politische Musik», Deutsche Zeitung Bohemia, 1 ${ }^{\text {er }}$ février 1918, p. 1 et suiv.

46. "My a cizina», Národní listy, 31 janvier 1918, p. 3.

47. Janáček, lettre à la rédaction de Národní listy, citée dans Jiří Ort, Leoš Janáček. Der späte Wilde, op. cit., p. 84. 
avoua être la cible d'attaques nationalistes allemandes ${ }^{48}$, mais réaffirma que le rôle du Hofoper était de s'opposer à tout «chauvinisme culturel» : «Ein österreichisches Theater, das vom Kaiser subventioniert wird, muß wohl allen Nationen unseres Staates, die beachtenswerte Kunstprodukte hervorbringen, einen Platz auf seiner Bühne einräumen ${ }^{49}$. "Cette opinion était également celle de Janáček : «Après tout, c'est l'opéra royal, c'est aussi le nôtre ${ }^{50}$ !» Jenůfa dut finalement sa représentation, le 16 février, à une intervention du jeune empereur Charles $\mathrm{I}^{\mathrm{e} 51}$.

\section{«Ein künstlerisches Erlebnis » ou «Mist ist Mist »?}

Ce fut un triomphe. Et, malgré ce que Max Brod relate dans ses mémoires ${ }^{52}$, il semble que Janáček ait été fort satisfait de la représentation. Le lendemain de la première, il remercia Reichenberger et promit : "c'en est fini pour ma part des récriminations ${ }^{53}$.» Le 20 février, il écrivit à Gabriela Horvátová, à propos de l'interprétation de Maria Jeritza : "J'ai enfin entendu et vu Jenůfa comme je me l'étais représentée ${ }^{54}$.» L'accueil critique fut plus mitigé. Certains, comme la critique du Neues Wiener Journal Elsa Bienenfeld, partageaient l'enthousiasme du public :

48. Clemens Höslinger («Zur Vorgeschichte der Wiener Jenufa-Premiere», art. cité, p. 416) reproduit la lettre suivante: "Während es aber so schwer möglich ist, Wagners herrliche deutsche Dichtungen zu hören, erfahre ich durch die Zeitungen, daß jetzt, mitten in der Zeit, da eine tschechisch-slovakische Armee gegen Deutschland-Österreich kämpft, da die tschechische Deklaration erschienen ist, die Tschechen und Südslawen den Reichsrat sprengen wollen, mit dem feindlichen Ausland liebäugeln, in der Zeit des großen Hasses des Slawentums gegen das Deutschtum, daß Sie in dieser Zeit eine tschechische Oper zur Verherrlichung das Allslawentums aufführen wollen!»

49. "Unterredung mit Hofoperndirektor Gregor», Neues Wiener Journal, 2 février 1918, p. 4.

50. Leoš Janáček, Korespondence s Gabrielou Horvátovou (Correspondance avec Gabriela Horvátová), Praha, Hudební matice, 1950, p. 73 : «No vždyt’ je ona i královskou, naší!»

51. Charles I ${ }^{\mathrm{er}}$, qui vit peut-être là une occasion de pacifier les Tchèques, donna suite à la demande de la Gesellschaft für Fürsorge für Kriegsinvalide de lui faire attribuer une partie des bénéfices de la première (Clemens Höslinger, «Zur Vorgeschichte der Wiener Jenufa-Premiere», art. cité, p. 413). Janáček espéra un temps que l'empereur lui-même assisterait à la représentation, mais il semble que la cour ait trouvé un moyen de ménager à la fois Tchèques et Allemands : on craignait que l'impératrice Zita, alors enceinte de l'archiduc Charles-Louis, ne supportât pas de voir représenter sur scène le meurtre d'un nouveau-né.

52. Max Brod, Streitbares Leben, op. cit., p. 274.

53. Clemens Höslinger, «Zur Vorgeschichte der Wiener Jenufa-Premiere», art. cité, p. 417.

54. Korespondence Leoše Janáčka s Gabrielou Horvátovou, op. cit., p. 74 : «Slyšel a viděl jsem konečnè Jenưfu ve svém díle.» 
Die Musik Janaceks hat ein eigenes Profil. Sie ist von Dworzak und Smetana weit entfernt, weniger reich im melodischen Einfall und in der musikalischen Erfindung, aber zielbewußt im Plan und vom Temperament des echten Dramatikers lebendig durchströmt ${ }^{55}$.

Pour Max Kalbeck, du Neues Wiener Tagblatt, "das Repertoire der Wiener Hofoper und weiterhin der deutschen Oper überhaupt [hat] eine wertvolle Bereicherung erfahren ${ }^{56}{ }^{\prime}$. L'hebdomadaire Der Montag qualifia Jenůfa de "Volkskunst im höchsten Sinne» et salua le tournant que représentait Jenůfa pour le Hofoper : «Endlich weht ein neuer Hauch, durch unser erstes Kunstinstitut. Endlich ${ }^{57 ! » ~ D e ~ n o m b r e u x ~ c r i t i q u e s ~}$ prirent également soin de souligner que la représentation fut un événement «artistique» :

Es war gar keine Gelegenheit zu einer Demonstration gegeben. Denn wo ein Kunstwerk, und besonders ein Theaterstück, unmittelbar packt, gibt es kein Publikum, und zumal in Wien nicht, das zwischen dem Eindruck und dem Applaus noch Zeit zu politischen Räsonnements fände $e^{58}$.

Mais, si tous s'accordèrent à reconnaître la qualité artistique de la représentation, la plupart des critiques exprimèrent surprise et incompréhension : "Hie und da leuchten und blitzen aus der sehr sorgsamen Partitur Kraft und Schönheit auf. [...] Aber sonst geht es wieder mühsam den langen eigensinnigen und eigenwilligen Weg der höchst asthmatischen Wortmelodie weiter ${ }^{59}$.» Le 8-Uhr-Blatt reconnut l'originalité de Janáček mais déplora lui aussi la monotonie causée par les Wortmelodien ${ }^{6}$, une opinion partagée par le critique du Prager Tagblatt :

Das Prinzip der "gesprochenen Wortmelodie", das der Komponist leider ernst genommen hat, erwies sich als wenig förderlich, die Übersetzung des Textes als ungleichwertig und durch falsche Betonung erschwert; die musikalische Erfindung im Grunde als schwächlich, selbst dort, wo sie aus slowakischen Volksmelodien schöpft ${ }^{61}$.

On retrouve les même arguments sous la plume de Julius Korngold, dans la Neue Freie Presse et de Richard Batka, dans le Fremdenblatt, pour qui célébrer Janáček comme le nouveau grand compositeur tchèque

55. Elsa Bienenfeld, «Janaceks Oper „Jenufa“", Neues Wiener Journal, 17 février 1918, p. 12.

56. M[ax] K[albeck], «Janaceks „Jenufa“», Neues Wiener Tagblatt, 17 février 1918, p. 10.

57. «Jenufa ", Der Montag, 18 février 1918, p. 2.

58. «Hofoper», Wiener Neueste Nachrichten, 18 février 1918, p. 7.

59. «Die vielumstrittene Oper „Jenufa“», Illustrierte Kronen-Zeitung, 17 février 1918, p. 7 et suiv.

60. «Jenufa. Erstaufführung in der Hofoper», Neues 8 Uhr-Blatt, 18 février 1918, p. 3.

61. "Janáčeks „Jenufa“ an der Wiener Hofoper», Prager Tagblatt, 17 février 1918, p. 5. 
était dangereux : "Wenn die czechische Musik auf dem betretenen Wege fortschreitet, liegt die Gefahr nahe, daß sie für die übrige Menschheit unfaßbar und damit ungenießbar wird ${ }^{62}$.»

C'est de la presse nationaliste que vint la condamnation la plus vive. Pour Karl Schreder, du Deutsches Volksblatt, l'œuvre n'était pas digne du Hofoper :

der Edelsinn der Deutschen [wird] mißbraucht und unsere ärgsten Feinde triumphieren, wenn es sich wieder ereignet, daß sie einem ihrer nationalen Werke Eingang in einen der vornehmsten deutschen Kunsttempel erschlossen haben.

Il conclut, avec une évidente mauvaise foi :

Das aus Wienern bestehende Publikum verhielt sich dem Werke gegenüber kühl und spendete nur den Darstellern verdienten Beifall. Die in Menge anwesenden Stammesgenossen des Komponisten feierten diesen, doch gelang es auch ihnen nicht, unter sich eine übermäßige Begeisterung zu erzielen ${ }^{63}$.

Le Pester Lloyd dénonça le triomphe d'un «opéra paysan slovaque» à Vienne :

Man erwies [Jenůfa] einen Dienst, indem man sie, den Ausbund aller musikalischen Schöpferkraft slawischen Geblüts, nur dieses Geblütes halber angriff, indes rund und ehrlich zu sagen war, daß es sich bloß um die Einführung eines musikfreien Machwerks handelte, das nichts anderes beweise, als daß ein Volk wie dieses (das sich nur an seinem Hasse zu erlaben mag) auch die Fähigkeit verliere mußte, in der Tonkunst etwas Ewiges hervorzubringen. [...] Mist ist Mist, ich kann mir nicht helfen ${ }^{64}$.

Les efforts de Janáček et de ses alliés viennois pour évacuer la dimension politique furent vains. Pour la presse tchèque, la représentation de Jenůfa à Vienne était un événement de première importance. Národní listy affirma que la représentation de 1916 au Théâtre national de Prague n'avait pas à rougir de la comparaison avec celle du Hofoper, mais laissa également transparaître un sentiment d'infériorité : «l'un des nôtres a pu prendre la parole devant une audience étrangère de connaisseurs et

62. Richard Batka, «Jenufa», Fremdenblatt, 17 février 1918, p. 1.

63. Karl Schreder, «Jenufa», Deutsches Volksblatt, 17 février 1918, p. 2 et suiv.

64. Hans Liebstöckl, «Wiener Brief», Pester Lloyd, 5 mars 1918, p. 3. 
a eu ses faveurs ${ }^{65}$.» Et c'est justement cette attitude qui exaspéra Zdeněk Nejedlý : «Si nous possédons une œuvre d’art nationale qui mérite vraiment notre fierté, nous ne devrions pas nous incliner devant des étrangers et nous exalter parce qu'elle a été "reconnue" ${ }^{\text {". }}$." Selon lui, Jeni̊fa n'était pas cette œuvre d'art nationale et le fait qu'elle ait été choisie par le Hofoper laissait à penser que les motivations étaient à chercher hors de la sphère artistique, suspicion renforcée par le rôle joué par les «juifs allemands de Prague» dans la représentation de Jenůfa à Vienne, laquelle avait dénaturé le caractère tchèque de l'opéra et l'avait transformé en «caricature».

Si l'on considère que Jenůfa ne fut représenté que neuf fois au Hofoper entre février et mai 1918 puis disparut de l'affiche ${ }^{67}$, la controverse que déclencha cet «opéra national tchèque» dans les rangs des nationalistes allemands et tchèques, fait l'effet d'une tempête dans un verre d'eau. Il n'en reste pas moins qu'elle est emblématique de l'exacerbation des tensions nationalistes, parfois poussées jusqu'à l'absurde, qui caractérisaient les derniers mois de l'Empire austro-hongrois.

65. «Janáčkova „jeji pastorkyňa“ ve Vidni», Národní listy, 19 février 1918, p. $2:$ :[...] že se tu předcizím, zhýčkaným forem dostává $k$ slovu jeden $z$ nás, že je po zásluze přiznivě vitán $[\ldots] »$.

66. Zdeněk Nejedlý, «Janácková opera v videňské opeře. Př́spěvek $\mathrm{k}$ otázce sebeurčení národů», Česká stráž, 8 mars 1918, p. 4 : «Máme-li nějaké národní umělecké dílo, jež jest opravdu té hodnoty, abychom byli na ně pyšni, pak nepotřebujeme se skláneti pred cizinou a býti u vytržení nad tím, že takové dílo „uznává"».

67. L'opéra fut remis à l'affiche du Staatsoper autrichien en 1926, deux ans après la représentation au Staatsoper de Berlin sous la direction d'Erich Kleiber et au Metropolitan Opera de New York sous la direction d'Artur Bodanzky. 